\title{
Tüketim Kültürünün Yerel Kültürler Üzerindeki Etkisinde Alışveriş Merkezlerinin (AVM) Rolü: Dubai Mall
}

\author{
Başak Özorala,
}

\section{Özet}

Bu çalışmanın amacı; modern yaşamın ve tüketim kültürünün mikro ölçekte örneği olan alışveriş merkezlerinin (AVM), yerel kültür üzerindeki etkilerini araştırmaktır. Makalede nitel araştırma yöntemlerinden etnografik yöntem kullanılmıştır. Çalışmada Birleşik Arap Emirlikleri'nin (BAE) önemli kenti Dubai'de bulunan dünyanın en büyük AVM'lerinden Dubai Mall örneği seçilmiştir. Dubai'de yaşayan yerli halktan rastgele ve kartopu örneklem yöntemi ile seçilen 150 Emirati vatandaşının, Dubai Mall'a yönelik görüşleri yarı yapılandırılmış soru tekniğine dayalı görüşmeleri analiz edilmiştir.Araştırma sonuçlarına göre AVM'lerin bulundukları çevredeki geleneksel günlük yaşamın yerleşik düzenini ve bireylerin davranış modellerini değiştirdikleri saptanmıştır. Araştırma sonuçları, Emirati vatandaşların küreselleşme sürecinin etkisi altında radikal sosyal ve kültürel değişimler deneyimlediklerini göstermektedir. AVM'ler, Emirlikler'de yaşayan halkın yaşam tarzında, sosyal ilişkilerinde ve davranışlarında gözlenen değişimi hızlandıran, yaygınlaştıran kurumlar olarak ön plana çıkmıştır. Dubai Mall örneğinde, AVM'lerin sundukları hizmetlerin zorlayıcı etkisi ile geleneksel ve tutucu yerel halkların dahi batı kültürünün izlerini taşıyan yeni tutum ve davranışlara yöneldiği de elde edilen sonuçlar arasındadır.
Anahtar Kelimeler

Küreselleşme

Dubai

Alı̧veriş Kültürü

Kültürel Değişim

Makale Hakkında

Geliş Tarihi: 22.01 .2020

Kabul Tarihi: 10.06.2020

Doi: $10.18026 /$ cbayarsos.678852

\section{The Role of Super Malls on Consumerism in Local Cultures: Dubai Mall}

\begin{abstract}
The aim of this study is investigate the influence of shopping malls, which are the samples of modern life and consumerism, on local culture. In this paper one of the qualitative methods, an ethnographic method, is used. One of the biggest shopping malls in the World, Dubai Mall in the UAE was taken as an example. Semi structured questions, which are about their idea on Dubai Mall, were asked to 150 interviewers, who are Emirati citizens. This paper shows that shopping malls have changed the routine of the traditional life and citizens' behavior in Dubai. The result of the study demonstrates even very conservative and traditional societies have changed at the age of globalization. The shopping malls have penetrate the daily life of Emiratis and guide them in accepting of new identities and attitudes which represent Western culture.
\end{abstract}

Keywords

Globalization

Dubai

Consumerism

Cultural Change

About Article

Received: 22.01.2020

Accepted: 10.06.2020

Doi: 10.18026/cbayarsos.678852

a İletişim Yazarıbozoral@ticaret.edu.tr

• Dr. Öğr. Üyesi, İstanbul Ticaret Üniversitesi, Siyaset Bilimi ve Uluslararası İlişkiler Bölümü. ORCID: 0000-0003-4620-9275 


\section{Giriș}

Tüketim, küreselleşme sürecinin belirleyici özelliklerinden biridir. Pek çok sosyal bilimci, günümüz toplumunu egemen küresel kültürünün etkisi altındaki "tüketim toplumu” olarak tanımlamıştır (Baudrillard, 2004). Tüketim toplumunun mikro ölçekte analiz edilmesi için şehirlerin en büyük ve görkemli yapıları olan Alış Veriş Merkezleri'nin (AVM) işlevlerini incelemek yararlı olacaktır. Günümüzde şehirlerin merkezi sayılan AVM'ler, bireylerin alış verişle birlikte eğlence, sosyalleşme ve kültürel etkinliklere katılma gibi bütün ihtiyaçlarını bütünsel düzeyde karşılayabilmektedir. Bu özellikleri nedeniyle de günlük yaşamın odak noktasında bulunan AVM'lerin kapitalizm ideolojisine uygun olarak sadece ekonomik işlevi yoktur. AVM'ler, bireylerin toplumsal statü, kişilik ve kimliğine de yön veren tüketim pratiklerini, bir başka tanımı ile post modern toplumların en önemli özelliğini oluşturmaya başlamıştır. Bu anlamı ile tüketim, bireyin ihtiyaçlarının giderilmesini aşan boyutu ile sosyal varlığını kanıtlaması, fark edilmesi için bir gerekliliğe hatta amaca dönüşmüştür. Küreselleşme süreci, yeni anlamların üretilmesini sermaye akışını sürekli hale getirmek için kullanmaktadır. Ulus, din ya da kültür gibi kavramların bu akışı engellemesinin önüne geçilmesi küresel düzenin de sürekliliğini sağlar. Dolayısıyla tüketim kültürü, dünyanın her yerinde monolitik bir yapı olarak eş zamanlı yayılmaktadır. Yerel kültürün başat ve katı olması nedeniyle toplumsal değişimlerin donabildiği Orta Doğu ülkelerinde dahi tüketim kültürü beklenmedik şekilde hızla yayılmaktadır.

Günümüzde AVM'ler bütün dünyada iç tasarımı ve dekorasyonuyla tüketiciler için cazibe merkezi olmanın ötesinde modern yaşamın kamusal ilişkilerini düzenleyen ve bunu kontrol eden mekanlara dönüşmüşlerdir (Vural-Yücel, 2006:105). Gündelik yaşamın bir parçası olarak gidilen bu merkezler, bütün şehirlerde sosyal ve kültürel dinamiklerinin kilit noktası ve önemli ticari ve kamusal bir alan olarak hizmet vermektedirler.

AVM'lerin şehirlerin en önemli alanlarına dönüşmesi tüketim kültürü üzerinden yeni toplumsal ilişkiler ağının ortaya çıkmasına neden olmuştur. Bu yeni toplumsallık biçiminin karakteristik özelliği, kültürlerinin benzeşmesi ve bireylerin aynı tüketim merkezinde buluşmalarıdır. Post modern dönemde, tüketim bir yaşam tarzı olarak gösterilmiştir. Ancak tüketim toplumunda bireylerin temel ihtiyaçlarının karşılanması ikincil bir amaç olarak değerlendirilmekte ve üretmekten daha öncelikli bir hedef olarak tüketmenin, yapısal dönüşümüne önem verilmektedir (Duman, 2016). Sermayenin küreselleşmesi ile birlikte malların sınırları aşan hız ve tedarik kolaylığı, internet teknolojisi kitlesel düzeyde yoğun bir tüketimin yaşanmasını kolaylaştırmıştır. "Kapital Küresel Market" olarak AVM'ler uluslararası markaların benzer tüketim kalıplarının dayatıldığı yerlerdir. Bu çabaların doğal sonucu; yerel kültürün parçalanması ya da hiç olmazsa ortaya çıan küresel bir kültürün, toplumsal düzeyde kabul görmesidir. Bu monolitik kültür, bireylerin gündelik hayatlarının planlı bir şekilde tasarlanması, maddi ihtiyaçların ikincilleşmesi ve gerçeğin imajlara dönüşerek bir tüketim çılgınlığının yaşanmasını ortaya çıkarmıştır. Bu çalışmanın temel sorusu farklı kültürlerde AVM'lerin pompaladığı tüketim kültürüne karşı tepkilerin nasıl olduğudur. Araştırma Arap coğrafyasında yer alan son derece geleneksel ve muhafazakâr toplumların pek çok konuda Batı kültürünü eleştirseler de tüketime yönelik tutumlarının Batılı ülkelerden farklı olmadığını BAE örneğinde ortaya koymaktadır. Tüketim kültürü ve AVM'ler üzerine yapılan çalışmalarda Müslüman ülkelerle ilgili araştırma sayısı oldukça azdır, Orta Doğu'da kapitalizmin kalbi olarak yükselen Dubai'de yapılan bu araştırma literatüre bu anlamda bir katkı sağlayacaktır. 
Makalede ilk olarak Dubai'nin ekonomik yükselişi ve Orta Doğu'da yaşanan değişim rüzgârlarının etkisiyle diğer bölge ülkeleri için nasıl bir rol model olduğu açılanacaktır. Ardından bölgede modern AVM'lerin yükselişi, geleneksel marketlerin ve alışverişin nasıl değiştiği anlatılacak ve dördüncü başlıkta dünyanın en büyük ikinci AVM'si olan Dubai Mall ve etkileri tartışılacaktır. Beşinci kısım çalışmanın yöntemi üzerinedir ve ardından bulgular açıklanacaktır. Bu kısımda görüşme ve gözlemlerin sonuçları ortaya konacak ve ardından çelişkiler üzerinde durulacaktır. AVM ve tüketim kültürünün değiştirdiği sosyal, kültürel ve ekonomik ilişkileri olumlu bulan ve eleştiren katılımcıların görüşleri açıklanacaktır. Sonuç ve tartışma bu bilgiler ekseninde yapılacak ve tüketim kültürünün ve market ekonomisinin kurallarının en tutucu ve geleneksel toplumlardan biri olan Arap Emirlikleri'nde bile yaygın bir şekilde kabul gördüğü açıklanacaktır.

\section{Dubai ve Tüketim Kültürü}

Arap ve İslam kültürü üzerine inşa edilmiş geleneksel bir sosyal yapıya sahip olan Dubai, aynı zamanda modern kapitalizmin, dolayısıyla tüketim kültürünün Orta Doğu'daki merkezi durumundadır. Bu özellikleri, Dubai'yi geleneksel toplum yapısının küresel değerlerle buluştuğu ilginç bir örnek durumuna getirmiştir.

$\mathrm{BAE}$, son otuz yıldır turizm, inşaat, finans ve enerji alanlarında büyük bir gelişim göstermiştir. Ekonomik gelişme ile birlikte şehirleşme artmış, BAE'nin en önemli şehri olan Dubai, alt yapısı, ticaret merkezleri ve teknolojik yatırımlarıyla Orta Doğu'nun en cezbedici şehirlerinden birine dönüşmüştür. Ekonomik refah artışı ve küreselleşmenin yoğun etkisi altında olan Körfez Ülkeleri içinde belki de kültürel ve sosyal yaşamda da en ciddi dönüşümler BAE'de gözlenmiştir.

BAE'de yaşayan yerli halk bir başka ifade ile Emirati vatandaşlarının ekonomik gelişimlerine bağlı zenginlikleri, Batılılaşma, tüketim kültürünün yaygınlaşmaya başlaması ve toplumsal düzeyde kabul görmesi ile sonuçlanmıştır (Aqil, Ağustos 2018). Emirlikler'de yaşanan kültürel, demografik ve sosyal yapıdaki değişim, geleneksel ve muhafazakâr kültür ile küreselleşme sürecinin taşıdığı tüketim kültürünün harmanlanarak yeni tüketici modeli oluşmasını sağlamıştır.

Dubai'nin nüfusu 2015 yılı itibariyle 40 sene içinde \%1000 oranında bir hızla artmış ve 2 milyonu geçmiştir (Elessawy, Nisan 2017). Heterojen bir nüfus yapısına sahip Dubai'de Hintli, Endonezyalı, Filipinli, Afrikalı göçmenlerin yanı sıra Avrupalı, Amerikalı ve Orta Doğu'lu expatların sayısı da hızla artmaktadır. Farklı kültür, etnik ve sınıflara bağlı insanların çok kültürlü yaşama ilişkin özellikleri, Emirlikler'in yerel kültüründe ve yaşam tarzlarında yaşanacak değişimi işaret etmektedir.

Kaliteli ve marka ürünlere sahip mağazaları ile tüketime yeni bir boyut kazandıran AVM'ler, yüksek kar getiren yapılar olmaları nedeniyle 1980'li yılların başından itibaren Dubai' de hızla yayılmıştır. AVM'ler alışverişin dışında sinema, dinlenme, toplumsallaşma ve diğer insanları görebilme gibi pek çok amaca hizmet eden merkez konumundadırlar. Mekânsal olarak alışverişin kültürel bir pratiğe dönüşmesi için iklimlendirilmiş mekânın, doğa koşullarının oluşturduğu zorluklar ve kirlilikten uzak, steril ve konforlu bir çevre sağlaması gerekmektedir. AVM'ler tam da bu nedenlerle insanların yeni buluşma ve iletişim mekânları olmuştur (Millar, 1998). Dolayısıyla AVM'lerde tüketim kültürü, küresel orta sinıfla ilişkilendirilmiştir (Vadakepat, 2013). Ancak, orta sinıf kültürünün tüm dünyada 
yaygınlaşması ile ABD ve Batı Avrupa'daki pratiklerinin incelenmesine karşılık (Cohen, 2003; Hovland \& Wolburg, 2015; Hamilton \& Dennis, 2005), batılı olmayan ülkelerdeki orta sınıfın kültürleri ve yaşam pratikleri üzerinde fazla durulmamıştır (Robbins, 2005). Aslında tüketici haklarının önemsenmesi ve orta sınıf üzerinden tüketim kültürünün pompalaması, Batılı yaşam tarzının dünyanın farklı geleneksel toplumlarına kendi imgesini yeniden düzenleme çabasından başka bir şey değildir. Tüketim kültürünün bu şekilde yayıldığ tarafından ortaya konulmuştur (Lundgren, 1988; Ritzer, 2008). Tüketim kültürünün bir uzantısı olarak AVM'ler, çağdaş şehir yaşamının bir parçası olarak değerlendirilmektedir.

AVM'ler çağdaş şehrin mekânsal olarak kurgulanmasını etkilemektedir. Bu süreç, şehirlerin yapılarındaki değişimin ile sosyal ve kültürel hayatında etkilenmesine neden olmaktadır. Modern alanlar ve yaşam merkezleri, halkın eski yaşam tarzlarını devam ettirmesini zorlaştırmakta, küresel iletişimin mesajını güçlendirterek dönüşümü kolaylaştırmaktadır (Koolhaas, 2001). Dolayısıyla, hava alanları, AVM'ler gibi özel bölgeler kozmopolit modernliğin küresel orta sınıfa yayıldığı alanlar olmuşlardır. Bu tarz yerlerin homojen yapıları birbirine benzerdir ve yerel yapılardan kopuktur. Birbirinin aynı olan bu yapılar aslında küreselleşmenin bir yönü ile Batılılaşma olduğunu da gösterirler (Abaza, 2001).

\section{Dubai'de Modern AVM'lerin Gelişimi}

1980'li yıllara kadar Dubai ticaretinin ve alış verişin merkezleri "Souq" adı verilen eski tarz kapalı çarşılardı. Dubai'de ilk modern süper AVM olan Al Ghurair Mall 1981'de açıldı. Yaklaşık on yıl sonra ülkenin en büyük AVM'si olan Majid Al Futtaim, Deira şehir merkezinde açldı. Bu AVM'de dünyanın en büyük marketlerinden biri olan Carrefour bulunmaktadır. Bu projelerinin başlaması önce yoğun eleştiriler almıştır. Nüfusu az olan şehirlerde yabancıların ya da turistlerin de pek de ziyaret etmedikleri bu bölgede, süper bir AVM açılması mantıklı bulunmamıştır. Ancak zaman içinde beklenmedik bir hızda büyüyen Dubai herkesi şaşırtmış, ardından da AVM'ler tüm Dubai'ye yayılmıştır. Sonunda dünyanın en büyük alış veriş merkezi olan Dubai Mall ekonomik krizin ortasında açılmasına rağmen müthiş bir başarıya ulaşmıştır. Dubai Mall, Dubai'deki lüks malların yüzde ellisini tedarik ederken, dünyanın en çok ziyaret edilen alış veriş ve yaşam merkezlerinden biri olmuştur. Dubai Mall, 2019 yılında 84 milyon ziyaretçiyi ağırlamıştır. (Mitchell, 2019). Dubai'de halen sistemli bir şekilde bir şekilde mega AVM yapımı için planlama yapılmaktadır. Mohammed Bin Rashid Şehrinde Dubai Mall'dan daha da büyük yeni bir AVM yapımı sürmekte ve 2020 yılında yapılacak Dubai Dünya Expo için gelenlerin ziyaret edebileceği yeni AVM ihtiyacının karşılanması amaçlanmaktadır. 2000'li yıllarda açılan diğer AVM'ler, Marina Mall ve The Galleria, Al Maryah Adasında yeni bir lüks alış veriş merkezi, Dünya Ticaret Merkezi, The Community Mall, Deerfields Townsquare'dir (Duncan, 2013).

Dubai'de toplam 96 AVM vardır. Her biri farklı bir konsept üzerinden inşa edilen yapılarda tema parkları, kültürel aktiviteler, sergi alanları, oyun alanları, güzellik merkezleri, masaj terapileri, tiyatro ve sinema alanları ve dünya mutfağının en seçkin lezzetlerinin bulunduğu bölümler bulunmaktadır. Turistlerin ilgisini çektiği kadar olduğu kadar yerli halkında gündelik hayatının bir parçası olan AVM'lere her yaştan insan gelmekte ve vakit geçirmektedir. 


\section{Dubai Mall}

$\mathrm{Bu}$ çalışmada, küresel kültürün, geleneksel formları ve katı kültürel yapıları nasıl değiştirdiğini incelemek için BAE'nin en büyük şehri Dubai'de bulunan Dubai Mall örneği araştırılmıştır. Dubai Mall, şehir merkezinin büyük bölümünü kaplayan mega bir proje olarak 12 milyon $\mathrm{m}^{2}$ olarak inşa edilmiştir ve toplam büyüklüğü 200 futbol sahasına eşittir. Dubai Mall'da 1200 satış mağazası iki büyük departmant store 3,77 milyon metre kare serbest dinlenme alanı ve 200' den fazla restoran bulunmaktadır. Ayrıca AVM'ye ait olan 5 yıldızlı The Adress Dubai Oteli'nin, 244 odası 449 apartmanıyla 14000 araba kapasiteli otoparkı bulunmaktadir.

Dubai Mall'ın ünlü moda markalarına yer ayırdığı Fashion Avenue'da $440.000 \mathrm{~m}^{2}$ alanda bulunan ve Fransız stilini yansıtan Galeries Lafayette ve Amerika'nın önde gelen mağazası Bloomingdale, bu lüks mağazaların Orta Doğu'daki tek şubesidir. AVM'nin souq adı verilen ve ayrı bir bölümde yer alan, yürüme yolu üzerinde mücevher aksesuar mağazaları ile geleneksel Arap kostümleri ve el işleri satan mağazaları yer almaktadır. Ayakkabı katında 250 farklı modacıya ait koleksiyonlar 40 farklı mağazada satılmaktadır. Ayrıca 828 metre yüksekliğindeki Burj Khalifa 2010 yılından bu yana dünyanın her yerinden ziyaretçi çekmektedir. Burj Khalifa'nın 148. katında bulunan dünyanın en yüksek seyir terası, ziyaretçileri kendine çekmektedir. Bu bina Dubai Mall'ın merkezi konumundadır. Bu özelliklere sahip Dubai Mall'da Geç Jura Dönemi'nden kalan dinazor iskeleti sergilenmekte, Dubai Mall'a gelen ziyaretçiler 155 milyon yaşında 24,4 metre uzunluğunda ve 7,6 metre yüksekliğindeki Dubai Dinozorunu da yakından görme imkanına sahip olmaktadır. Bu özellikleri Dubai Mall'ı alış veriş, eğlence ve kültür hayatının merkezi olarak milyonlarca insanın ziyaret etmesini sağlamaktadır.

Dubai Mall, Emirlikler gibi tutucu bir yapıya sahip bir toplumun sosyal ve kültürel hayatındaki değişimi ve küreselleşme sürecinin bu toplum üzerindeki etkisini de gösteren kamusal bir mekandır. Bu nedenle, modernitenin toplumsal etkilerinin incelenmesi ve dönüşümün araştırılması açısından önemlidir. AVM'leri küreselleşme sürecinin kaleleri olarak tanımlamak yanlış olmayacaktır. Bu bağlamda, AVM'ler küresel kültürün sahip olduğu ekonomik, sosyal ve kültürel özellikleri mikro ölçekte bünyesinde barındıran, yayılmasını sağlayan ve topluma kabul ettiren, modern dünyayı ve şehirleşmeyi temsil eden kurumlardır.

\section{Çalışmanın Yöntemi}

$\mathrm{Bu}$ çalışma Dubai Mall örneğinde Emirlik vatandaşları için AVM'lerin sosyal, ekonomik ve kültürel yaşamlarını nasıl etkilediğini incelemeyi ve anlamayı hedeflemektedir. Araştırma soruları, Emiratilerin tüketim kültürü ve çağdaş Emirati kimliği ile ilgili yaklaşımlarını, tutum ve düşüncelerini anlamak için Dubai Amerikan üniversitesinden rastgele örneklem metodu ile seçilen öğrencilere ve kar topu örneklem metodu ile bulunan, öğrencilerin yaşadığı mahalle ve semtlerindeki ailelerine ve komşularına sorulmuş ve örneklem grubu 150 Emirati vatandaşı olarak belirlenmiştir. Üst orta gelir grubunu temsil eden öğrenciler ve aileleri genellikle Dubai Mall'a yakın bölgelerden oturmaktadır Dubai'nin değişimini ve dinamizmini en iyi şekilde temsil ettiklerinden araştırma için uygun bulunmuşlardır.

Araştırmada, nitel araştırma yöntemlerinden etnografik yöntem kullanılmıştır. Etnografik yöntem, belli bir insan grubunun kültürel düzeyde anlama ve betimle çalışmalarıdır. Bu çalışmalarda, grubun kullandığı kültürel kodları ve iletişim boyutunun incelenmesi ile bilgi, görüş ve düşünceler ile karşılaştırılarak gündelik yaşam pratiklerinin bütün yönleri ile 
araştırılması amaçlanmaktadır (Kartarı, 2017). Etnografik yöntemde toplumların kültürel yapısı içinde bütünsel olarak derinlikli bir araştırma ile insan davranışlarının analiz edilmesi amaçlanmaktadır (Borg, 1999).

Görüşmeler iki ana grupta toplanmıştır. İlk grup görüşmeler öğrenciler ile yapılmış, ikinci grupta ise katılımcı ailelerin evlerine gidilerek görüşme yapılmıştır. Görüşmeler Dubai Mall ve tüketim kültürüne ilişkin tutum ve davranışlarına yönelik derinlemesine araştırma yapma imkânı sağlamıştır.

Katılımcıların cevapları tüketici davranışları, eğlence, yemek, farklı yaş grupları aile ve cinsiyet ilişkilerine göre konu başlıklarına göre sınıflandırılmış, veriler sistematik bir şekilde sınıflandırılarak yorumlanmıştır. Araştırmada tüketiciler, alışveriş kavramı, mağazalar, Emirliklerin gelenek ve adetlerinde görülen değişimleri yansıtan davranışlar, özellikle AVM'lerde karşı cinslerin birbiriyle ilişkilere yönelik tutumları incelenerek muhafazakâr kadın erkek ilişkilerindeki değişim de incelenmiştir.

\section{Bulgular}

Araştırmada, Emiratilerin Dubai Mall'la ilgili deneyimleri toplanan bilgiler üzerinden analiz edilerek günümüz Emirlikleri'nin sosyal ve kültürel yapısı değerlendirilmiştir.

Araştırmaya katılanlar 20-35 yaş arası Emirati vatandaşlardır. Katılanların \%67'si erkektir. Kadınların oranı ise \%33 düzeyindedir. Araştırmaya katılan erkeklerin $\% 42,5^{\prime}$ u aylık gelirinin 20.000 dirhem (USD 5.444 ) ve üzeri saptanmıştır. Araştırmaya katılanların \%84,6'sı haftada iki ya da üç kez AVM'lere gittiğimi ifade etmiştir. AVM'lere gidenlerin \%50'si akşam, \%34'ü ise öğleden sonraları tercih ettiğini kalan \%16'l1k kısmı ise günün her saati gidebildiklerini açıklamıştır.

Dubai Mall, görüşmecilerin en fazla tercih ettikleri AVM'dir. 68,4\% civarında görüşmeci Dubai Mall'u tercih etmekteyken kalan \%31,6'sı ise Emirates Mall, İbn Battuta Mall başta olmak üzere farklı AVM'lere gitmektedirler. Araştırmaya katılanlar AVM'leri genellikle aileleriyle ziyaret ettiklerini belirtmiştir.

Katılımcıların AVM'de geçirdikleri süre içinde alışveriş, restoranlara gitmek, film seyretmek, kafelerde oturmak cevapları arasında herhangi bir cevap yoğunluk kazanmamıştır. Katılımcılar AVM'lere gitme nedenlerini pek çok farklı faaliyet ile açıklamıştır.

Katılımcların \%90'ı AVM'lere yerel kiyafetle gitmektedir. Kadınlar "abaya" olarak isimlendirilen siyah uzun elbiseleri, erkekler ise "tovb" adı verilen beyaz kıyafetleri tercih ettiklerini belirtmiştir. Katılımcıların çoğunluğu Dubai Mall'u sosyalleşmek, alış veriş yapmak, kültürel aktiviteleri takip etmek ve spor yapmak için sıkça ziyaret ettiğini söylemektedir. Dubai Mall'da bulunan buz pateni pisti özellikle genç ve çocuklara batılı tarzda spor yapma imkanını sağlayan ve filmlerde gördükleri hayat tarzını bizzat yaşama olanağı sunan bir alan olarak gençlerin gitme nedenleri arasında yer almaktadır. Katılımcılar çölün ortasında buz pateni pisti olmasını ve Kanada ve Amerika gibi ülkelerde popüler olan buz hokeyi kurslarının verilmesini ilginç bir deneyim olarak değerlendirmektedir. $\mathrm{Bu}$ deneyim, coğrafi farklılıklardan kaynaklanan kültürel farkların küreselleşme süreci ile yok edilmesinin çarpıcı örneklerinden birine işaret etmektedir. Emiratiler ne tarihsel ne de geleneksel anlamda deneyimleri olmayan bu spor dalına ilgi göstermekte, yabancılar da kendi ülkelerinde alıştıkları yaşamı Dubai de sürdürebilmenin konforunu yaşamaktadır. Bu faaliyet bir yönü ile insanlar ve kültürler arası bir bağ oluşmaktadır. 
Benzer şekilde; Dubai Mall'da oluşturulan yapay gölde, ufak tekne gezintisi yapılması, belirli saatlerde devasa ve ilgi çekici su gösterilerinin düzenlenmesi de önemlidir. Gösterilerin yerli Arap müziğinin yanı sıra batılı klasik ve modern müziklerinin eşliğinde gerçekleşmesi, kültürlerin karışımına örnek gösterilebilir.

Dubai Mall'da Arap, Amerikan, Avrupa kültürlerinin yansımaları bulunmaktadır. Mağazaların isimleri hem İngilizce hem Arapça yazılmıştır, bu durum, AVM'lerin diller ve kültürler arası bağlantıda fonksiyonel rolünü göstermesi bakımından önemlidir. Dubai Mall'un sunduğu bir diğer hizmet olan sinema bölümü -modern anlamda 1970'li yıllardan beri Dubai'de sinemaların bulunmasına karşılık, kadınların sosyal hayata katılımının sınırlı olması açısından popüler değillerdi- Emirati kadınlarının AVM'de yalnız başına rahatça gezmelerine ek olarak sinemaya giderek dünya kültürleriyle tanışmalarını sağlamaktadır. Katılımcılar, aile üyeleri ile birlikte yapabilecekleri aktivitelerin AVM'ler sayesinde iki kat fazla yapabildiklerini açıklamış ve yiyecek, içecek ve ev eşyalarının alınması, ünlü restoranlara gidilmesi, arkadaşlarla ve tanıdıklarla buluşulması gibi aktiviteleri bulunduklarını ifade etmişlerdir.

AVM'ler farklı ekonomik ve sosyal sınıflardan insanın bir araya gelebildiği mekanlardır. Bu yaşam merkezleri daha önce toplumsal düzeyde ortak mekanlarda bir araya gelmeyen kadın ve erkeklerin aynı ortamda bulunabildiği sosyal ilişki imkânı bulduğu mekanlar olmuştur. Bu açıdan AVM'lerin Emirlikler'de yaşayan farklı toplum kesimlerinin özellikle kadın ve erkeklerin birbirlerini gözlemledikleri, sosyal ve kültürel paylaşımlar yaşadıkları mekanlar olarak birleştirici kaynaştırıcı bir etkisi olduğu söylenebilir.

Dubai Mall'da kafe ve restoranların çoğu franchise şubelerdir. Bu yerlerde uluslararası standartlarda dünya mutfakları ve yeme içme alışkanlıkları AVM'de temsil edilmektedir. Emirati vatandaşları bu kafe ve restoranlarda kendi mutfak kültürlerinin dışında farklı deneyimler yaşamakta ve farklı ülkelerin yemeklerini tadarak yeni kültürlerle tanışmaları sağlanmaktadır. AVM içindeki geleneksel Arap kahvesi yerine İngiliz çaylarının servis edildiği Avrupai çay evleri vardır. Ayrıca yeşil çay ve diğer uzak doğu çaylarının satıldığı kioslar Emiratilerin de ilgisini çekmekte ve onlara yeni yeme içme alışkanlıkları kazandırmaktadır.

Muhafazakâr ve geleneksel Arap toplumunda genç kız ve erkeklerin birbirleri ile AVM'de karşılaşmaları, tanışabilmeleri ve beğenilerini ileterek telefon numaralarını vermeleri mümkündür. Emiratili kadın katılımcılar daha önceleri Emirati toplumunda bulunmayan bir özgürlük ortamını Dubai Mall'da yaşadıklarını ve kendilerini daha modern ve çağdaş hissettiklerini belirtmişlerdir.

Emirati aileleri misafirlerini Dubai Mall'daki restoran ve kafelerde ağırladıklarını, doğum günlerini bu mekanlarda kutlamaya başladıklarını söylemişlerdir. Bu durum, Emirati kültürüne yabancı bir durumdur. Misafirin evde ağırlanması ve evlerde bir araya gelerek yemek yenilmesi ve ikramlar, Emirati kültürünün en belirgin özelliklerinden sayılabilir. Bir başka kültürel dönüşüm ise doğum günü ve mezuniyet kutlamalarının yeni keşfedilmiş olmasıdır. Katılımcılar, bu tarz aktivitelerin batılılaşmanın etkilerini gösteren ve kendi kültürlerine tezat bir durum olduğunu ancak keyifli olduğu için hızla yayıldığını belirtmiştir.

Emirati kültürünün en belirgin özelliklerinden biri ev sahipliği ve misafirperverliktir. Ayrıca kadınların ve erkeklerin farklı odalarda ayrı ayrı bulunduğu toplantılarda, erkeklerin sıkça bir araya gelerek pek çok konuyu konuştukları hatta evlilik, iş kurma kararlarının alındığı, 
sorunların çözüldüğü "Mejlis" adı verilen toplantılar oldukça bilinen bir yerel gelenektir. (Obydan, 2012). Ancak AVM kültürü restoran ve kafelere buluşmanın rahatlı̆̆ını sunarken, misafir ağırlamaya yönelik geleneklerin yavaş yavaş azalması ile küresel, modern yaşam tarzına geçiş, yerel kültürü dönüştürmekte belki de yok etmektedir.

Tipik Emirati geleneği olan kadın ve erkeğin toplumsal alanda ayrı ayrı bulunması, AVM'lerde uygulanmamaktadır. Hatta mağaza çalışanları, garsonlar, banka ve ofislerde görev yapanlar da kadın erkek ayrımı olmadan çalışabilmektedir. Arap kültüründe katı olan kadın erkek ayrımı bu mekânlarda ortadan kalkmakta, bu durum yaşamın diğer alanlarında da yavaş yavaş etkisini göstermektedir. Geleneksel Emirati tipi restoranlar ailelerin mahremiyetini koruyan perde ve kilimlerle ayrılmış bölümlerden oluşur ve müşteriler birbirlerini görmez, oysa bu tarz bir uygulama AVM'lerde görülmemektedir. Emiratiler için bu durum yabancı bir unsur olarak, Batı kültürünün bir özelliği olarak kabul edilse de kabul görmüştür ve giderek yayılmaktadır.

Moda, geleneksel Emirati ve İslam kültüründe olmayan bir kavramdır. Oysa AVM'lerde vitrinlerde sergilenen ve yabancı ziyaretçi ya da çalışanların giydiği kıyafetler aksesuar ve ayakkabılar Emiratiler tarafından takip edilmektedir. Ünlü moda mağazalarının şubeleri Dubai Mall'da son moda tasarımlarını satmaktadır ve büyük satış cirolarına ulaşmışlardır. Özellikle alış veriş̧ festivali döneminde her yıl milyonlarca yabancı turistin yanı sıra pek çok Emirati, popüler modacıların ürünlerini satın almaktadır. Evlerde yapılan toplantılarda, kutlamalarda, iç mekanlarda, abayalarının altında bu son moda kıyafetler, ayakkabı ve çantalar kullanılmaktadır. Amerika ve Avrupa'nın tanınmış modacıları Dubai Mall'da oldukça popülerdir. Genç Emiratiler modayı takip etmekte hatta dışarda, gidecekleri yere göre pantolon, jean, ceket gibi kıyafetleri de giyebilmektedir. Emirati aileleri artık kızlarına pantolon giymelerine izin vermektedir. Daha önce kadınların pantolon giymeleri yasakken, özellikle genç kızlar uzunca bir gömlekle pantolon, -sıklıkla jean- giymekte, başlarını örtmektedir. Bu giyim tarzı, Batı tarzı yaşam stilinin Emirati kültürüne girmesine örnek gösterilebilir.

Katılımcılar "AVM'ler inşa edilmeden önce ne yapardınız?" sorusunu genellikle ailelerinin evlerinde toplanıp onlarla vakit geçirdiklerini, akrabalarını ziyaret ettiklerini, eski stil kapalı çarşı sebze ve baharat pazarı ve olan Bur Dubai'ye gittiklerini, sahilde yürüyüş yaptıklarını ve gençler de futbol oynadıklarını söyleyerek cevaplamışlardır. Katılımcıların çoğu Dubai'deki hayatın AVM'ler yapılmadan önce daha basit olduğunu belirtmiştir. Gençler AVM'lere gitmenin aile ziyaretlerinden çok daha çekici olduğunu, buralarda eğlenceden yemeğe, kültürel faaliyetlerden spora kadar yapacak pek çok aktivite olduğunu dile getirmiştir. AVM'ler özellikle gençlerin boş zamanlarında yaptıkları aktiviteler açısından yaşanan değişimler açısından oldukça etkilidir.

Dubai Mall açıldığında gençlerin tutum ve davranışlarında önemli bir değişime neden olmuştur. AVM'nin içinde bulunan Souk Bahar isimli geleneksel Arap Çarşısı, alışverişin yanında yapay göl, buz pateni pisti ve spor salonları ile farklı aktiviteler yapma imkânı sunmuştur. Gençlerin buluşma noktası ve vakit geçirmesi açısından cazibe merkezi olan Dubai Mall diğer AVM'lerden farklı olarak pek çok aktiviteyi aynı mekân içinde sunmaktadır. Dubai Mall'ın hafta içi de kalabalık olması sahip olduğu bu imkanlar ile açıklanabilir.

Katılımcılardan bazıları Dubai Mall'ın mimarisinden iç ve dış mekanların estetik yapısından etkilendiklerini ve mekân insan ilişkisi içinde büyük ve yüksek alanların kendilerine ferahlık 
verdiğini ifade etmiştir. Avrupai stilde tasarlanmış kafeler, gençlerin kendilerini daha modern hissetmelerine neden olmakta ve katılımcılar geleneksel yaşamları dışında farklı deneyimler yaşama imkânı bulmaktadır. Amerikan Teksas restoranında rodeo izleyerek biftek yemek, Çin tarzı döşenmiş minimalist bir kafede yeşil çay içebilmek, gençlerin kendilerini "şanslı" olarak hissetmelerine neden olmaktadır. Bu nedenle küreselleşmenin karşılığının "bu imkanlara sahip olmak" düşüncesi gençlerin benimsediği yaygın bir düşüncedir.

Dubai Mall'da yer alan Dubai'nin en büyük kitapçısı Kinokuniya Bookstore da ziyaretçilerin en çok tercih ettikleri mekanlardandır. Bu kitapçıda dergi veya gazete okumak, yeni çıkan kitapları takip edebilmek, tüm kırtasiye çeşitlerini bulabilmek, farklı dillerden yayınlara ulaşabilmek mümkündür. Çocuk kitapları bölümünde zengin bir koleksiyona sahip kitapçının okuma alışkanlığı olmayan Emiratilerin davranışlarına etkisinin olumlu olduğu söylenebilir. Virjin gibi dünyaca ünlü müzik ve magazin mağazalarında son çıkan albümler, konser biletleri, teknolojik aletler, tüm dünyada popüler olan oyunlar ve aksesuarlar bulunmaktadır. Bu ürünler, batı tipi bir kültürün özelliklerinin tanıtımını yaparken, özellikle Emirati gençleri dünyaca ünlü sanatçıların müziklerini bu sayede tanımakta, popüler kültürün kahramanlarını yansıtan ürünleri satın alarak küresel kültürün bir parçası olmaktadırlar.

Dubai Mall'un üçüncü katında bulunan akvaryum ve su altı müzesi de ziyaretçi akınına uğrayan yerlerin başında gelmektedir. 10 milyon litre su alabilen büyüklükteki akvaryumda bulunan 140 çeşit deniz canlısı, bu alandaki en geniş koleksiyona sahip su altı müzesini oluşturmaktadır. Cam tabanlı botlarla tur yapmak ya da tüplü dalış ile köpek balıklarıyla yüzmek gibi heyecan verici aktiviteler bu bölümü AVM'nin en kalabalık bölümlerinden biri haline getirmiştir.

AVM'nin iç mekân tasarımı çok geniş ve yüksek tavanlıdır. Modern heykel ve resim örnekleriyle süslenmiş bu iç mekanlar Emiratililere daha önce pek alışık olmadıkları sanat eserleriyle temas etme imkânı sağlamaktadır. İç mekânın bir bölümünde yer alan şelalede dalış yapan erkek heykelleri bulunmaktadır. Çağdaş sanat olarak nitelendirilecek bu heykeller Arap kültürü açısından yenidir ve katılımcılar bu eserlerin hepsi için beğenilerini dile getirmiştir.

Araştırmada AVM'lerin sahip olduğu fiziksel koşullar ile bireylerin deneyimleri arasında olumlu bir ilişki olduğu saptanmıştır. Çağdaş mimari ile tasarlanmış sanat eserleri, yeme içme kültürü, eğlence formatları, araştırmaya katılan Emiratilerin \%84'ü tarafından hayatı algılayışlarında belirgin olumlu farklılıklara neden olduğunu ifade etmişlerdir. Kadınların eşleri yanında olmadan alış verişe çıkabilmeleri, toplum içinde yemek yiyebilmek, çocukları oyun alanına birakarak karı koca dolaşabilmek ya da sinemaya gitmek gibi deneyimler Emirati kültüründe yaşanan değişimi hızlandırmış ve günlük hayat rutinlerini değiştirmelerine ve yaşam tarzlarında farklılıklara yol açmıştır.

Katılımcılar, Dubai Mall'da ülkeye özgü geleneksel ürünlerin satıldı̆̆ı bir alanlar olmasına rağmen yabancı bir karakter taşıdığını düşünmektedir. Ankete katılanlar, yabancı ve küresel markaların mağazalarından alışveriş etmeyi tercih ettiklerini, bu ürünleri kullanmanın onlara toplum içinde hem sosyal statü ve hem de prestij sağladığını belirtmişlerdir. Ayrıca tanınan yabancı markaların kalitesine güvendiklerini ve bu ürünlere para harcamaktan kaçınmadıklarını ifade etmişlerdir. Emiratilerin her türlü zevke hitap eden ürünlere yönelik olarak görüşleri ise ihtiyaçlarını kusursuz bir şekilde temin etmeleri yönündedir. Bununla birlikte katılımclardan \%70'ten fazlası sadece vitrinlere bakarak zaman geçirmeyi sevdiklerini 
ve sıklıkla ihtiyaçları olmayan ürünleri de vitrinlerde görmeleri nedeniyle satın aldıklarını dile getirmiştir. Dubai Mall ve diğer AVM'ler açıldıktan sonra katılımcılar, çok daha fazla tüketim yapmaları nedeniyle giderlerinin arttı̆̆ını hatta alış verişin başlı başına bir eğlence ve aktivite haline geldiğini ifade etmiştir.

Bayramlarda ve Batı kültürü için de önemli günlerden sayılan yılbaşı gibi günlerde AVM'ler tıpkı batı ülkelerinde olduğu gibi özenle süslenmekte, Christmast figürleri ve müzikleri her yerde çalınmaktadır. Cadılar Bayramı Halloween'da maskeler, korku efektleri mağazaların dekorlarında görülebilir. Sevgililer günü olarak anılan Saint Valentine Day'de, AVM'ler kırmızı kalpli figürlerle, balonlarla süslenmektedir. Bu kutlamalar, yerel Emirati kültüründe olmayan ve İslami değerlere de oldukça aykırı öğeler taşımasına karşılık yavaş yavaş kabul görmeye ve yayılmaya başlamıştır. Aynı şekilde Müslümanların kutsal ayı olan Ramazan boyunca AVM'lerde kuran okunması ve ramazana özgü açlış kapanış saatleri uygulanması ve etkinler yapılması önemlidir. Yemek alanları, kafeler, restoranlar dışarıdan görünmeyecek şekilde kapatılmakta, sadece oruç tutmayan yabancılar için hizmet vermektedir. Özet olarak; AVM'ler özel gün ve bayramlarda yapılan kutlamalar ile kültürler arası bir kapsayıcılık geliştirmiştir. Farklı değerlerin ve inançların buluştuğu mekanlar oldukça işlevseldir. Her inanç, gelenek, kutsal gün ya da kutlama AVM'lerde kendine yer bulabilmekte hatta özel pazarlama teknikleriyle alış verişi canlandırmak için araç olarak kullanılmaktadır.

\section{Çelişkiler}

Araştırmaya katılanların çoğu aynı zamanda Dubai Mall'un yarattığı negatif etkilerden de bahsetmiştir. Gençlerin büyük çoğunluğu Dubai Mall'a belli bir amaç için gitmediklerini ve sadece vakit geçirmek için zamanlarını boşa harcadıklarını söylemektedirler. Katılımcılar, Dubai Mall'un Emirati kültürünü yansıtmadığını, bunun sonucu olarak buraya gelen turistlerin bu tarz bir ortamda Arap ve İslam gelenekleri hakkında doğru bir izlenim edinemeyeceğini belirtmiştir. Bazı katılımcılar Dubai Mall'daki mağazaların yerel üreticilerin ürünleri yerine, uluslararası yabancı ünlü markaları satıyor olmasının sakıncalarında da bahsetmiştir. Hatta Arap mallarının satıldığı bölümde sadece turistlere yönelik hediyelik ürünlerin bulunduğunu ve gündelik hayata yönelik Emirati ürünlerinin ise satılmadığını, bu durumum yerel üreticiler açısından olumsuz etkilere yol açtığını belirtmişlerdir.

Bir katılımcı, “Dubai Mall'un yaşam maliyetlerini ve giderleri arttırdığını” iddia etmiştir. "Gerekli olmayan pek çok malın diğer tüketicilerin ve kampanyaların etkisi ile satın alındığını" söylemiştir. Dubai Mall üst gelir düzeylerindeki insanların gittiği bir AVM olsa da periyodik olarak yapılan indirimler ve özel kampanyalar alt gelir gruplarındaki müşterileri de çekmektedir.

Ayrıca modanın kültürel tezatlıkların ve karşıtlıklara örnek olarak gösterilmesi gerektiğini belirtenler de vardır. Bazı katılımcılar, Emiratilerin batı kıyafetleri satan mağazalar yüzünden kendi kıyafetleri konusunda aşağılık kompleksi hissederek batılı gibi giyinmeye başladıklarını düşündüğünü söylemişlerdir. Ayrıca mağaza vitrinlerinde yer alan reklam ve imajların Emirati kültür ve geleneklerine aykırı mesajlarla dolu olduğunu da belirtilmiştir. Reklamlarda "abaya"lı kadınların görünmemesini yadırgadıklarını ifade etmişlerdir.

Diğer bir olumsuzluk ifadesi ise yabancıların, özellikle bekar Asyalı işçilerin Emirati kadınlarına tacizkar davranış ve bakışlarının yarattığı rahatsızlıktır. Katılımcıların bazısı bu yüzden AVM'nin aileler için farklı günlerde ziyarete açık olması gerektiğini iddia etmişlerdir. Benzer şekilde katılımcılardan biri kültürel çatışmanın olduğunu bunlardan en önemlisinin 
de yabancı dil olduğunu belirtmiştir. Mağazalarda çalışanlar yabancılardır ve yabancı dilde, İngilizce konuşmaktadırlar bunun Emirati vatandaşlar için bir sınır anlamına geldiğini, kendilerini yeterli derecede anlatamadıklarını ve yabancı dilde konuşma zorunluluğunun ortaya çıtı̆̆ını söylemiştir.

Dubai Mall'un yakınlarında yaşayan aileler trafiğin ve kalabalığın artmasından şikâyet etmektedir. Pek çok insan evlerine gitmeden önce Mall'a gitmekte ve akşam yemeklerini evde yemek yerine dışarıda yemeği tercih etmektedir. Bu gelişmeler komşuluk ilişkilerini de etkilemiştir. Katılımcıların ifadelerine göre; eskiden birbirlerine teklifsiz gidip gelebilen komşular görüşmek için randevu almak zorundadır. Dubai Mall'un çevresinde büyük siteler yüksek apartmanlar yapılması nedeniyle komşularının yabancı olduklarını ve birbirlerini tanımadıklarını söylemektedirler. Katılımcılar AVM ziyaret saatlerinin kişilere göre farklı olduğunu söylemişlerdir. Saat 18.00 ve 21.00 arasında ailelerin daha sık ziyaret ettiği AVM'den gençler ve bekarlar ise 23.00 civarı dönmektedirler. Bu durumun akşamları bir araya gelen aile üyelerinin bazılarının artık ortamda bulunmaması ve bu kültürel yapının bozulması anlamına geldiğini göstermektedir. Bu durumun Dubai'deki toplumsal ilişkileri değiştirdiğini, yakın aile ve akraba bağlarını zayıflattığını söylenebilir.

Benzer olarak mobilya mağazaları da koltuk takımından bardağa kadar ev döşemesinde batılı tarzdaki trendleri yansitan ürünlerle hizmet vermekte ve geleneksel kilim ve yer minderlerinin yerini bu mobilyalar almaktadır. Ev dizaynları ve mekân döşemelerinde Batı kültürümün etkilerinin artmasında bu mağazaların etkisi büyüktür.

Yiyecek içecek alış verişi de Dubai Mall'daki marketten yapılmakta balık, sebze ve meyve halinin yerini Carrefour, Jeant gibi marketler almaktadır. Bu tarz marketler daha önce Emirati'lerin bilmedikleri sebze ve meyveleri ve gıda ürünlerini satmakta, Emirati mutfağının değişmesinde etkili olmaktadır. Hazır yemekler, evde yemek yapılmasına alternatif olarak kadınların yemek yapmaya ayırdıkları zamanın azalmasında ve günlük rutinin değişmesinde etkilidir.

Tüm bu özellikleriyle katılımcılar AVM'lere ihtiyaç olduğunu, kendileri ve aileleri için gereken her şeyi bulabilecekleri bu mekanların rahatlı̆̆ ve sundukları konfor ile günlük hayatlarının vazgeçilemez bir parçası olduğunu dile getirmişlerdir.

Bir şehirdeki oteller, üniversiteler, müzeler, camiler ve diğer önemi toplumsal yapıların mimarisi o bölgenin kültürünü ve ulusal kimliğini yansıtan en temel sembollerdir. Bu tanımın 1şığında Dubai Mall'un mimari yapısı değerlendirildiğinde yerel Emirati kimliğini değil, ulusal özelliklerini yitirerek modern fonksiyonların küresel dönemde görülen özelliklerini taşımakta olduğu görülür.

Aslında AVM'lerde bulunan ve satılan mallar, hatta AVM'lerin kendisi belli bir kültürel kimliğini temsil etmemektedir. Küreselleşmiş bu organik yapı, AVM'lerden alış veriş yapmak Körfez ülkelerindeki ulusal kimliğin kollektif anlamda yeniden oluşumunun göstergesi olarak kabul edilebilir (Auge, 2009). Ayrıca bu AVM'ler bireysel kimliklerin de yeniden inşasında önemli rol oynamaktadır. Bireyin seçimleri tüketim toplumuna eklemlenmekte yeni yaşayış tarzlarına uyum sağlamak ise geleneksel değerler yerine küresel yapıya entegre olmayı sağlamaktadır. Başka bir deyişle bireyin seçimleri, örneğin çantalarda, saatlerde, giysi ve mücevherde belli başlı markaları kullanması, hem sınıfsal farkını hem de geleneksel toplumdan ne derece ayrıştığını ve koptuğunu göstermesi açısından önemlidir. 
Modern küresel dünyada sosyal statü tüketicilerin zevkleriyle belirlenir hale gelmiştir. Geleneksel Emirati toplumunda bireylerin prestijleri ve sosyal statüleri sahip aileye, aşiret ilişkilerine ve kendi başarılarıyla ulaştıkları durumla belirlenmektedir. Artık yavaş yavaş Emiratili bireylerin sahip olduğu ürünler, yaşam tarzı, evi ve arabası gibi değerler sosyal statüsünü belirleyen unsurlar olmaya başlamıştır. Bu durum tüketim kültürünün Emirati toplumu üzerindeki güçlü ve dönüştürücü etkisini göstermektedir.

\section{Sonuç ve Tartışma}

Dubai Mall gibi AVM'ler insanları tüketim kültürü etkisi altına alarak yeni alışkanlıklar geliştirmesine neden olan geleneksel kültürün barındırdığı yaşam pratiklerinin değişmesini sağlayan mekanlardır. Dubai Mall pek çok ailenin günlük yeme içme alışkanlıklarını değiştirmiştir. Evde yemek pişirmek yerine AVM'de yemek, yerel ve geleneksel tatlar yerine farklı mutfakları tatmak günlük hayatın alışılagelmiş düzenini değiştirmiştir. Aile içindeki üyelerin birbirleriyle ilişkileri, rolleri ve sorumlulukları da bu durumdan etkilenmiştir. Sinemada film izlemeye ya da paten kaymaya gitmek gibi batı kültürünün öğesi olan aktivitelere katılmak da günlük hayatın bir parçası olmuştur. AVM'lerde zaman geçiren insanlar ihtiyaçları olmadığı halde alış veriş yapmaya başlamış, tüketim artmıştır. Kısacası Dubai Mall aile üyelerinin eğlence ve boş zamanlarını geçirme konusunda yaşadıkları değişimi net olarak etkilemiştir. Ayrıca kadının sosyal yaşamdaki pozisyonunun yaşadığı evin dışına çıkması, eşi olmadan toplumsal alanlarda görünmesinde AVM'lerin etkisi büyüktür. Emirati kültürel kimliği konuşulan dil, kadın erkek ilişkileri, davranış değiş̧imleri ve sosyal yaşamın küresel kültürün kuşatması ile şiddetli bir dönüşüm geçirmektedir. Bu dönüşümün gelecekte hızlanacağı söylenebilir. Modern yaşam tarzının geleneksel toplumda kabul görerek yayılmasında Dubai Mall gibi süper AVM'ler merkezi bir önem taşımaktadırlar. Küreselleşme yayılmacı etkisini ve tüketim kültürünü özellikle AVM'lerde pompalayarak Dubai örneğinde olduğu gibi geleneksel kültür formunu kısacası kültürel çeşitliliği ve farklı kültürel kimlikleri tehdit etmektedir.

\section{Kaynakça}

Abaza, M. (2001). Culture and the reshaping of public space in Egypt. Theory/Culture/Society 18: 97-122.

Aqil, K. (August, 2018). The Emergence of Hyper-Consumerism in UAE Society: A Socio Cultural Perspective, Perspectives on Global Development and Technology. 17(4):353 372.

Baudrillard, Jean. (2004). Tüketim Toplumu (Çev. H. Deliceçaylı ve F. Keskin), İstanbul: Ayrintı Yayınları.

Borg, W.R anda and Gal M. D. (1989). Educational Research, London: Longma Group.

Elessawy, F. (July 2015). Conference Paper (PDF Available) · Conference: The Annual International Conference of Geography Dept. Alexandria University, At Alexandria.

Cohen, L.(2003), A Consumers' Republic, New York: Random House.

Goss, J. (1999). Once-upon-a-time in a commodity world: An unofficial guide to Supermall of America. Annals of the Association of American Geographers 89: 45-75. 
Hamilton, C. \& Dennis, R. (2005). Affluenza: When Too Much Is Never Enough. Crows Nest; Allen \& Unwin.

Heron, T. (2008). Globalization, Neoliberalism and the Exercise of Human Agency. International Journal of Politics, Culture and Society, 28 (1-4), 85-101.

Lundgren, N. (1988). When I grow up I want a Trans-Am: Children in Belize talk about themselves and the impact of the world capitalist system. Dialectical Anthropology 13: 269276.

Kartarı A. (2017). Nitel Düşünce Ve Etnografi: Etnografik Yönteme Düşünsel Bir Yaklaşim, Hacettepe Üniversitesi İletişim Fakültesi Kültürel Çalışmalar Dergisi, 4(1): 207-220.

Koolhaas, R. (2001). Junkspace. In: Chung, CJ, Inaba, J, et al. (eds.) Harvard School of Design Guide to Shopping. Taschen, Köln.

Millar, D., Peter, J., Nigel, T., Beverley, H. and Michael, R. (1998). Shopping, Place and Identity. London: Routledge.

Obydan, Y. and Al-Mohanadi, H. (2012). Qatari Majlis: Traditions and costumes. Unpublished presentation at Qatar National Museum, Doha, Qatar.

Ritzer, G. (2008). The McDonaldization of Society. Thousand Oaks, CA: Pine Forge Press.

Robbins, R. (2005). Global Problems and the Culture of Capitalism. Boston, MA: Pearson Education.

Vadakepat, V. (2013). Multi-Culture Consumer Behaviour In The Abu Dhabi Markets. Education, Business and Society: Contemporary Middle Eastern Issues. 6(1): 42-54.

Vural T. ve Yücel A. (2006). Çağımızın Yeni Kamusal Mekanları Olan Alışveriş Merkezlerinde Eleştirel Bir Bakış, İTü Dergisi, Cilt:5, Sayı:2, s. 105, (97-106).

\section{Elektronik Kaynaklar}

Elessawy, F. (2017) The Boom: Population and Urban Growth of Dubai City. https://www.researchgate.net/publication/317564338 The Boom Population and Ur an Growth of Dubai City [Oct 24 2018].

Duman, M. Zeki (2016). Tüketim Kültürünün Gelişmesinde Artan AVM'lerin Etkisi, Uluslararası Sosyal Araştırmalar Dergisi The Journal of International Social Research, 9 (47),ss.806-815.http://www.sosyalarastirmalar.com/cilt9/sayi47 pdf/6ik sisat kamu isletme/duman mzeki.pdf (24.01.2018)

Duncan, Gillian. November 26, 2013, The evolution of UAE retail: From corner shops to mega mallshttps://www.thenational.ae/business/the-evolution-of-uae-retail-from-corner shops-to-mega-malls-1.652113 [accessed Oct 24 2018].

Mitchell, Bea.(2020) Emaar Malls announces rise in revenue and new destinations. Blooloop. https://blooloop.com/news/emaar-malls-revenue-new developments/ (11 Şubat 2020.) 